\title{
Distinguishing between Theory, Theoretical Framework, and Conceptual Framework: A Systematic Review of Lessons from the Field
}

\author{
Dr. Charles Kivunja ${ }^{1}$, PhD. \\ ${ }^{1}$ School of Education, University of New England, Armidale NSW 2351, Australia \\ Correspondence: Dr. Charles Kivunja, PhD., School of Education, University of New England, Armidale NSW 2351, \\ Australia. E-mail: ckivunja@une.edu.au
}

Received: October 24, 2018

Accepted: November 26, 2018

Online Published: December 3, 2018

doi:10.5430/ijhe.v7n6p44

URL: https://doi.org/10.5430/ijhe.v7n6p44

\begin{abstract}
Across many years of teaching Research Methods and assessing many applications for admission into higher degree studies which require an understanding of theories, principles, strategies and skills needed to complete a higher degree such as a Masters or a PhD, one of the things I have found problematic for many students is the inability to articulate differences between theory, theoretical framework and a conceptual framework for a proposed research project. This paper uses experiential methodology to draw upon my experience in practice, and systematic literature review methodology to draw upon supporting scholarly literature by leaders in the field, to contribute to existing knowledge on the meaning of each of these concepts, and more importantly to distinguish between them in a study of Research Methods, and in particular as they relate to designing a research proposal and a thesis for a higher degree. The primary aim is to help the reader develop a firm grasp of the meaning of these concepts and how they should be used in academic research discourses. The review answers five questions. 1 . What does each of these terms mean? 2. When and how should each be used? 3. What purposes does a theoretical framework serve? 4. How do you develop a theoretical framework for your research proposal or thesis? 5. What does a good theoretical framework look like?
\end{abstract}

Keywords: theory, theoretical framework, conceptual framework, research proposal, thesis

\section{Introduction}

Either from marking assessment tasks of my Higher Degree Research (HDR) students that have to complete Research Methods to be allowed to apply for admission into a higher degree, or from evaluating research proposals as a member or chair of the Confirmation Panel or Committee that assesses applications for confirmation of candidature into a higher degree at my university, or as an External Examiner of theses from several universities, I have learnt that the concepts of theory, theoretical framework, and conceptual framework are among those topics on which we, as educators of HDR students, should spend a lot more time. Why? Because many students appear to have considerable difficulties with these concepts. For example, they use terms like my theory is, my conceptual framework is, my theoretical schema is, as though these terms are directly interchangeable. Most of them use these terms when in fact all they want to convey is how they have used some theories in their thesis or how they propose to use theory they consider relevant to their research. Some add to the confusion by saying things like my theory is phenomenology or my theory is grounded theory, and even my theoretical paradigm is - .... I say we need to spend more time on this topic because it appears not to have attracted much attention in the large amounts of good books that exist on Research Methods in education and the social sciences. It would also appear that much as it is widely accepted that Research Methods is a specialised subject where terminologies have specific meanings, this understanding tends to be relaxed when many authors write about using theories in their research, and they, for instance use the terms theory, conceptual framework and theoretical framework as though they all mean the same thing, and therefore interchangeable.

In everyday speech it is quite common for someone to say I have a theory, and by the end of the day a person might have claimed to have several theories. In Research Methods, however, very few of the very best scholars have a theory they can call their own. In education and the social sciences in particular, unless you have mastery of grounded theory methodology, chances are you would not be able to develop a theory. In consideration of this substantial challenge, I have designed this paper to achieve five objectives, which correlate to the five questions posed above. Firstly, it should help the reader to develop an understanding of what we mean by a theory and a theoretical framework for a research project. Second, it should help a distinction between a theoretical framework, 
and a conceptual framework. Thirdly, the paper makes it clear that whereas every good thesis should have a theoretical framework, every $\mathrm{PhD}$ thesis must develop and use one, because of the very important role a theoretical framework plays in the analysis and making meaning of your data. Fourthly, the paper explains how a theoretical framework for a research project is developed. Finally, I provide an example of the development of a real theoretical framework and explain how it could be applied in data analysis.

\section{Systematic Literature Review Methodology: What Is a Theory?}

A systematic review of pertinent literature provides the understanding that a theory is a generalised statement of abstractions or ideas that asserts, explains or predicts relationships or connections between or among phenomena, within the limits of critical bounding assumptions that the theory explicitly makes (Gabriel, 2008). The generalised statement brings together ideas, "interrelated concepts, definitions, and propositions that explain or predict events or situations by specifying relations among variables" (Glanz, 2008, p. 114). The ideas, concepts and themes, constitute a deep and broad base of knowledge in the discipline - which constitutes the theory. These ideas, concepts, and themes together comprise the theory, which enables us to explain the meaning, nature, relationships, and challenges asserted, or predicted to be associated with a phenomenon in an educational or social sciences context, so that an application of those attributes of the theory, enables us to understand the phenomenon and to act more appropriately (Asher, 1984), including ability to predict. In line with this understanding, Kerlinger and Lee (2000, p. 11) define and explain the meaning of a theory very well, as follows:

\section{A theory is a set of interrelated constructs (concepts), definitions, and propositions that present a systematic view of phenomena by specifying relations among variables, with the purpose of explaining and predicting the phenomena. \\ This definition says three things: (1) a theory is a set of propositions consisting of defined and interrelated constructs, (2) a theory sets out the interrelations among a set of variables (constructs), and in so doing, presents a systematic view of the phenomena described by the variables, and (3) a theory explains phenomena; it does so by specifying which variables are related to which variables and how they are related, thus enabling the researcher to predict from certain variables to certain other variables.}

The propositions and interrelationships of a theory that are explained very well in this quote of Kerlinger and Lee (2000) can be simplified by a metaphor. In the metaphor I would say that the generalisation made by a theory enables you to see the forest instead of just a single tree. However, the generalisations can occur at three levels of increasing sophistication in breadth and depth, known as micro-level, meso-level, and macro-level (Neuman, 1997). For example, at the micro level, theories explain relationships among individuals. A specific example would be theories about how students learn, because they make assertions about students' learning behaviours at the micro level. At the meso-level, theories try to explain interactions among groups at an institutional level. For example, a theory on how an educational institution functions would make assertions and predictions at a meso-level. Finally, at the macro-level would be theories that seek to explain relationships at a more aggregative level, such as across gender among a particular ethnic group, or students' performance at a state or national level.

A theory usually emerges from a long process of research that uses empirical data to make assertions based on deductive and inductive analysis of the data. Overtime, and on the basis of clearly stated assumptions, the observations from the research produce results that converge on findings about relationships, and these enable the researcher to formulate the core propositions from which the abstract theory is then generalised. The theory that emerges provides an intellectual, research-grounded basis for understanding, applying, analysing, and designing new ways to investigate relationships and to solve problems in educational and social sciences contexts. The assumptions, assertions, and predictions of relationships postulated by a theory become an intellectual base upon which research data can be grounded to search for meaning in future studies. The predictions in the theory can provide reason for research into problems that hitherto have not been investigated. They help researchers to consider what is important and critical in understanding real-life situations, as postulated by the theory, and how our knowledge and understanding of contexts in education and the social sciences can be used to explain behaviour and to solve problems. As explained by Jacard and Jacob (2010), each theory - its assumptions, tenets, assertions, propositions, predictions - comprises a common frame of reference that can be used by researchers in a particular discipline as to what is understood to be true or a basis for searching for meaning and truth in our lived experiences, and a well-grounded guide for research within the field. As well articulated by Glanz, (2017, p. 10), "Theory, research, and practice are part of a continuum for understanding the determinants of behaviours, testing strategies for change, and disseminating effective interventions". The three are inextricably interlinked. Theory enables researchers to name 
what they observe, to understand and to explain relationships and to make sense of human interactions. This understanding increases the body of knowledge in the field and provides a basis for further theorisation, research, and understanding.

\section{Characteristics of a Theory}

A good number of authors (e.g., Bunge, 1967; Hunt, 1991; Johnson \& Christensen, 2017; Popper, 1985; Reynolds, 1971; and Wacker, 1998) outline the essential ingredients of a theory. A review of their work suggests that for a body of assertions, descriptions or predictions of behaviour or relationships to qualify as a theory, it must meet the following characteristics:

- It has to be logical and coherent

- It has clear definitions of terms or variables, and has boundary conditions

- It has a domain where it applies

- It has clearly described relationships among variables

- It describes, explains, and makes specific predictions

- It comprises concepts, themes, principles and constructs

- It must have been based on empirical data

- It must have made claims that are subject to testing, been tested and verified

- It must be clear and parsimonious

- Its assertions or predictions must be different and better than those in existing theories

- Its predictions must be general enough to be applicable to and in several contexts

- Its assertions or predictions are applicable, and if applied as predicted, will result in the predicted outcome

- The assertions and predictions are not set in concrete, but subject to revision and improvement as social scientists use the theory to make sense of phenomena in their world

- Its concepts and principles explain what is going on and why

- Its concepts and principles are substantive enough to enable us to predict future events

\section{Theoretical Framework Defined: What Is a Theoretical Framework?}

A theoretical framework comprises the theories expressed by experts in the field into which you plan to research, which you draw upon to provide a theoretical coat hanger for your data analysis and interpretation of results. Put differently, the theoretical framework is a structure that summarizes concepts and theories, which you develop from previously tested and published knowledge which you synthesize to help you have a theoretical background, or basis for your data analysis and interpretation of the meaning contained in your research data. Swanson (2013, p. 122) explicitly asserts, "The theoretical framework is the structure that can hold or support a theory of a research study". The theoretical framework for your research proposal or thesis is not a summary of your own thoughts about your research. Rather, it is a synthesis of the thoughts of giants in your field of research, as they relate to your proposed research or thesis, as you understand those theories, and how you will use those theories to understand your data. In essence, the theoretical framework comprises what leaders in your field of research say about your research question, about the problem you plan to investigate, and might even include suggestions of how to solve that problem, including how to interpret the findings in your data. What those leaders say, helps you to develop an informed, and specialized lens, through which you examine your data, conduct the data analysis, interpret the findings, discuss them, and even make recommendations, and conclusions. Data analysis and interpretation in a HDR is an academic piece of writing and cannot be written as conversational dialogue. It must reflect academic rigor and skills. Situating your research findings within your theoretical framework helps you to provide that rigor and skills. You can look at the theoretical framework as a structure or a data mining lens that uses knowledge from research done to date in your field, to make sense of the data in your own research study.

\section{How does a Theoretical Framework Differ from a Conceptual Framework?}

Students often experience difficulties in their research proposals and even theses when they use the terms theoretical framework and conceptual framework. These concepts are often confused even among experienced researchers, so this paper makes a contribution to knowledge by helping the reader to avoid such confusion and get these terms right. 


\section{Meaning of Conceptual Framework and Differences between Conceptual Framework and Theoretical Framework}

A conceptual framework is the total, logical orientation and associations of anything and everything that forms the underlying thinking, structures, plans and practices and implementation of your entire research project. So, the conceptual framework comprises your thoughts on identification of the research topic, the problem to be investigated, the questions to be asked, the literature to be reviewed, the theories to be applied, the methodology you will use, the methods, procedures and instruments, the data analysis and interpretation of findings, recommendations and conclusions you will make (Ravitch \& Riggan, 2017). Thus, the conceptual framework is the logical conceptualization of your entire research project. Saying that it is a logical conceptualization means that a conceptual framework is a metacognitive, reflective and operational element of the entire research process. This in turn means that the conceptual framework involves high order consideration of the following questions and/or issues about your research:

1. What do you want to do in your research? For example, as articulated in your research topic.

2. Why do you want to do it? For example, why is it important to conduct that research? Why it is significant? What aims will it seek to achieve? Which specific objectives will it pursue? How much scope will it cover?

3. How do you plan to do it? For example, which methodology will you apply? Which methods will you use? Who will be your participants? How will you gather data? How will you analyse the data?

4. How will you make meaning of the data? For example, which theoretical framework will you use to analyse the data? Which software will you use? Which skills will you need?

5. Which worldview will you locate your research in? For example, will it be in the positivist or interpretivist paradigm; critical or pragmatic paradigm?

6. How will you report your findings? For example, in a research paper, or a seminar paper, or a conference paper, a book chapter, or a book or a thesis?

Thus, you can look at the conceptual framework as the logical master plan for your entire research project. It is noteworthy, as you can see from the above, that a theoretical framework is only a little sub-set of the conceptual framework. A helpful analogy might be, that while the conceptual framework is the house, the theoretical framework is but a room that serves a particular purpose in that house. The purpose of the room could, for example, be the kitchen, or living room, or bathroom or bedroom, or garage. While each room has a unique purpose, no single room can serve all the functions that a house serves. This analogy should help you to appreciate better, why these two terms should never be used interchangeably. Only in a one-room 'house', would the house and room be one and the same thing. Most houses are not built like that.

The conceptual framework is thus the umbrella term relating to all the concepts and ideas that occupy your mind as you contemplate, plan, implement and conclude your research project. Thus, whereas the conceptual framework could be the product of your own thinking about your research study, the theoretical framework comprises other people's theoretical perspectives that you interpret as relevant to your research, and in particular, helpful in your data analysis and interpretation. That is why the term conceptual framework is so all-inclusive, that trying to unpack it in your research proposal could be messy. And since most of the constituent parts of the conceptual framework have sections of their own which need to be addressed in the research process, there is no need of taking the risk of trying to unravel this complex set of concepts. For all your practical purposes, there is no need to explain your conceptual framework. It is too diverse, too big a task for you to explain in a research proposal or a thesis. The advice I give my students is to avoid using this term. You need to design and explain the theoretical framework for your PhD thesis. However, you are not required to explicitly discuss your conceptual framework.

\section{What is the Purpose and Importance of a Theoretical Framework for Your Research?}

The main reason you should develop a theoretical framework for your research is so as to have a scholarly foundation for all your sense making of the meaning contained in your data (Neuman, 1997). The theoretical framework provides a structure for what to look for in the data, for how you think of how what you see in the data fits together, and helps you to discuss your findings more clearly, in light of what existing theories say. It helps you to make connections between the abstract and concrete elements you observe in your data. For example, the theoretical framework helps you to raise questions such as, what do leaders in this field theorise about my research question? What existing theoretical ideas can I use to investigate and to understand my research problem? According to the theories, what should I be looking for in the data to answer my research question? Thus, the theoretical 
framework helps you to substantiate your argumentation. It helps you to justify what you say about the findings and recommendations. As I said earlier, the theoretical framework serves as a coat hanger for all your data analysis, interpretation of results and discussion of findings. I use the metaphor of the coat hanger to emphasise that it is the structure that you use to make the bits and pieces of your data hang together as one body of knowledge. Another helpful metaphor I could give you is that your research data are bricks lying haphazardly in the backyard, and your theoretical framework organises them into a particular structure - a wall of a house, a wall across territorial borders, a pier of a cathedral, an arcade into a shopping mall. In each of these four structures, the bricks are given a different meaning by the structure in which they hang. I invoke this metaphor here to emphasize that the theoretical framework is the structure which helps you to interpret the meaning contained in your data. For this reason, and to invoke another metaphor, the theoretical framework serves a very important purpose as a lens through which you focus upon your data and see the meaning embedded within the data. This lens can magnify the contents in the data, and reveal interconnections which make meaning in answer to your research question, and in addressing your research problem. Without this lens, chances are you could miss some of such interconnections.

The theoretical framework enables you to add depth to your data analysis by supporting what you say with reference to the theories advanced by people whose knowledge on your topic is much deeper than yours, and in many cases proven or unquestionable. It enables you to report your findings in an analytical, evaluative and creative way. This adds to the depth of your analysis and discussion of findings. It demonstrates your deep rather than surface understanding (Kivunja, 2015), of the meaning contained in your data. It helps you to frame your arguments in light of what can be normally expected and in consideration of what is most likely to be true. It deepens the academic and scholastic flavor of your arguments. To invoke Guba's (1981) criteria for good research, we can say that a theoretical framework helps the achievement of these criteria:

- It increases the credibility of qualitative data or the internal validity of your quantitative data.

- It may enhance the transferability of the findings from your qualitative data or external validity and generalizability of quantitative data analysis.

- It increases the confirmability of your findings in qualitative data or objectivity of your findings in quantitative data.

- It improves the dependability of your findings in qualitative data or reliability of findings in quantitative data.

An important purpose of the theoretical framework is that it gives you the opportunity to state your theoretical assumptions very clearly, so that your supervisors and thesis examiners will know what guided your data analysis and interpretation. Furthermore, in addition to spelling out the assumptions, you also articulate which variables you will analyze. This helps you to make your data analysis and interpretation more focused. Additionally, because, as I have said above, a good theoretical framework should be seen to emerge from your literature review, your development of the theoretical framework demonstrates to your supervisors and thesis examiners that you have mastery of the relevant literature, from which the theoretical framework emerged. Again, as I have said above, because your thesis is a piece of academic, scholarly writing, the theoretical framework gives you the opportunity to demonstrate your capability, as an emerging researcher, to intellectually transition from simply describing your data to engaging in higher-order cognitive analysis, evaluation and synthesis of your data, enabling you to abstract and to generalize your findings. Use of the theoretical framework enables you, not only to interpret the meaning found in your data, but to also evaluate the solutions you propose for solving your research problem, as well as the recommendations you make for solving the problem and for future research. Assertions made by your theoretical framework enable you to sort your data into those that are relevant and important for analysis to understand your research problem, and which ones are not. This enables you to demonstrate your contribution to knowledge and scholarship, and because this is what you get awarded a $\mathrm{PhD}$ for, that is why I said at the start of this paper, that a theoretical framework is a must for a $\mathrm{PhD}$ thesis.

\section{How do You Develop a Theoretical Framework?}

An existing theory is not likely to provide plausible explanations of the meaning contained in your data, without modification. This is because, by definition, a theory, as we saw earlier, is an abstraction, a generalization, and therefore, it is not content, or topic specific. In contrast, by definition, your theoretical framework is an analytical structure you put together or develop to suit your research purposes, which as you know, are to answer your particular research question and address your stated problem. Therefore, the best way to develop your theoretical framework is to conduct a thorough literature review so that your theoretical framework can emerge from that 
literature, as represented in the theoretical views expressed by leaders in the field in which your thesis is located (Scott $\&$ Usher, 2004). Whereas you might be able to identify a theory in the literature and borrow that for your data analysis, the preferred approach which demonstrates the critical mind and creativity capacity of a $\mathrm{PhD}$ graduate is to synthesise the contents of existing theories into one that is custom-tailored to your own problem statement and research question. This is a challenging task, but so are all the tasks expected of a PhD candidate. To accomplish this task, you review the theories that are relevant to your topic, research question and problem, and use the contents, that is the concepts, assumptions, assertions, models and predictions, to come up with a theoretical framework purposely tailored to the needs of your research study so that it helps you to explain the findings in your study. Asking yourself the following questions, should help you to develop an effective theoretical framework, tailored to your own data analysis needs:

- Is there a theory that can help me to make sense of the meaning of the data that I will gather to answer the research question/s?

- Are there theories that have been developed in the field of my research topic, or in similar topics that might inform an understanding of my research question, my research problem and data analysis?

- What do experts in the field of my proposed research say about the problem I want to investigate?

- What do they say about the research questions I want to investigate, from theoretical perspectives?

- What do they say are the key variables to be investigated?

- Which assumptions, definitions, and propositions are in these leading scholars' theories, and how can I make them explicitly relevant to my research question, research problem, and data analysis?

- How can I modify what they have said, so as to come up with my own theorization about the meanings contained in my research data?

- Have I defined the key concepts in my theoretical framework?

- Does the theoretical framework I am developing address the research questions and hypotheses of my research? (i.e. If you have developed hypotheses).

- Does the theoretical framework I am developing address my research problem?

- Have I included in my theoretical framework all the key theories and analytic models in literature that relate to my study?

- Will the use of this theoretical framework enable me to analyze and discuss the findings in my data?

- Does the theoretical framework have a logical structure and make academic sense?

- Is my theoretical framework easily applicable to my data analysis?

- Does my theoretical framework encompass all the key variables or factors in my data?

- Does my theoretical framework enable me to explain the meaning contained in my data?

- Have I used the latest data available on the theoretical aspects of my planned research?

- Given my theoretical framework, which data shall I include in the analysis, and which data shall I exclude, and why?

\section{What does a Theoretical Framework Look Like?}

I think that a good way to facilitate your understanding of what a theoretical framework looks like is to outline an example. The example I have chosen is designed to help you understand how you can take an existing theoretical model, and re-frame it so that it serves as the theoretical framework for your own research. Here the example chosen is Kivunja's (2015) Constructivist Teaching Model, and an explanation is given on how it was developed into the theoretical framework to be used in a study that sought to investigate how teachers in 15 selected schools applied constructivist teaching principles and strategies in their teaching.

In Teaching, learning and assessment, Kivunja (2015), presents a model that represents what teaching and learning should look like in a constructivist classroom. As my overarching research question is: How do teachers in selected primary schools in New South Wales (NSW) apply constructivist principles and practices in their teaching, this model appears to provide a perfect fit for developing the theoretical framework that I will use to analyze data in this research. The model is illustrated in Figure 1. As illustrated in Figure 1, Kivunja (2015) proposes that in a constructivist classroom, active learning takes place and a highly dynamic teaching and learning environment is created. For example, students are busy, and actively engaged in constructing their own understanding. They are 
given opportunity to plan, do and review activities and concepts they learn. Students participate in learning activities as partners in knowledge construction, in a self-regulated learning way. Learning strategies are student-centered, providing scaffolding. They comprise rich learning tasks and involve cooperative learning teams. The strategies used by the teacher are challenging and try to extend the children's understanding of what they learn. The strategies are not only interesting but motivational. The strategies encourage cooperative rather than individualistic learning. The teacher is less important than the students, and is a multi-talented, facilitating, self-reflecting practitioner. Their role is to motivate the children, and help them to engage in social construction of knowledge. The teacher tries to become a reflective practitioner. S/he sets high expectations for all the children in their class and challenges each one to work towards achieving their personal best. S/he uses cooperative learning strategies to develop team spirit and social skills among the children. The classroom environment and behavior are goal-oriented and on-task, with high expectations of every student by the teacher. Activities in the classroom are learner-focused and the instructions are democratically given. Classroom tasks are goal-oriented, motivational, tolerant, diverse inclusive, orderly and encourage social interdependence. Assessment is for learning and is authentic, targeting higher-order learning. It allows for self-assessment, peer assessment and provides a lot of feedback to the children to help them realize the progress they are making. Assessments give children a variety of tasks to choose from and freedom to complete them in different ways. Reporting is designed not only for student improvement, but also teacher improvement. The report cards consist of grades that make sense to the children, parents, the school and other stakeholders. Empathy is reflected in the comments provided in the report card. Reporting targets the learning outcomes that the children are expected to achieve as per their learning stage. The reports are accurate and comprehensive. These processes are all interrelated in a dynamic quality-learning environment that plans and facilitates intellectual quality learning in which children are engaged in the construction of deep knowledge and understanding of ideas, concepts, issues and skills that have significance in their lives at school and beyond school. These practices are consistent with the three dimensions of the NSW Quality Teaching Model (NSW DET, 2013). These practices are also supported by Carnes (2011, p. 72), who says that in a classroom in which constructivist active learning is taking place, children 'attend classes that set their minds on fire'. In agreement with Kivunja (2015) and Carnes (2011), Boyd (2013) asserts that the role of a teacher in a classroom where constructivist active learning is taking place: "is like a great artist. Someone who is able, through their chosen profession to inspire both students and peers to learn lifelong. Someone who is able to achieve the right balance in the choices they make in the learning opportunities and challenges they create. Is able to put together a sometimes eclectic group of tools and strategies to achieve the 'light bulb flash' learning moment as well as sustained interest in learning individually, in small groups or whole classes, for one student or an entire class" (p. 3). 


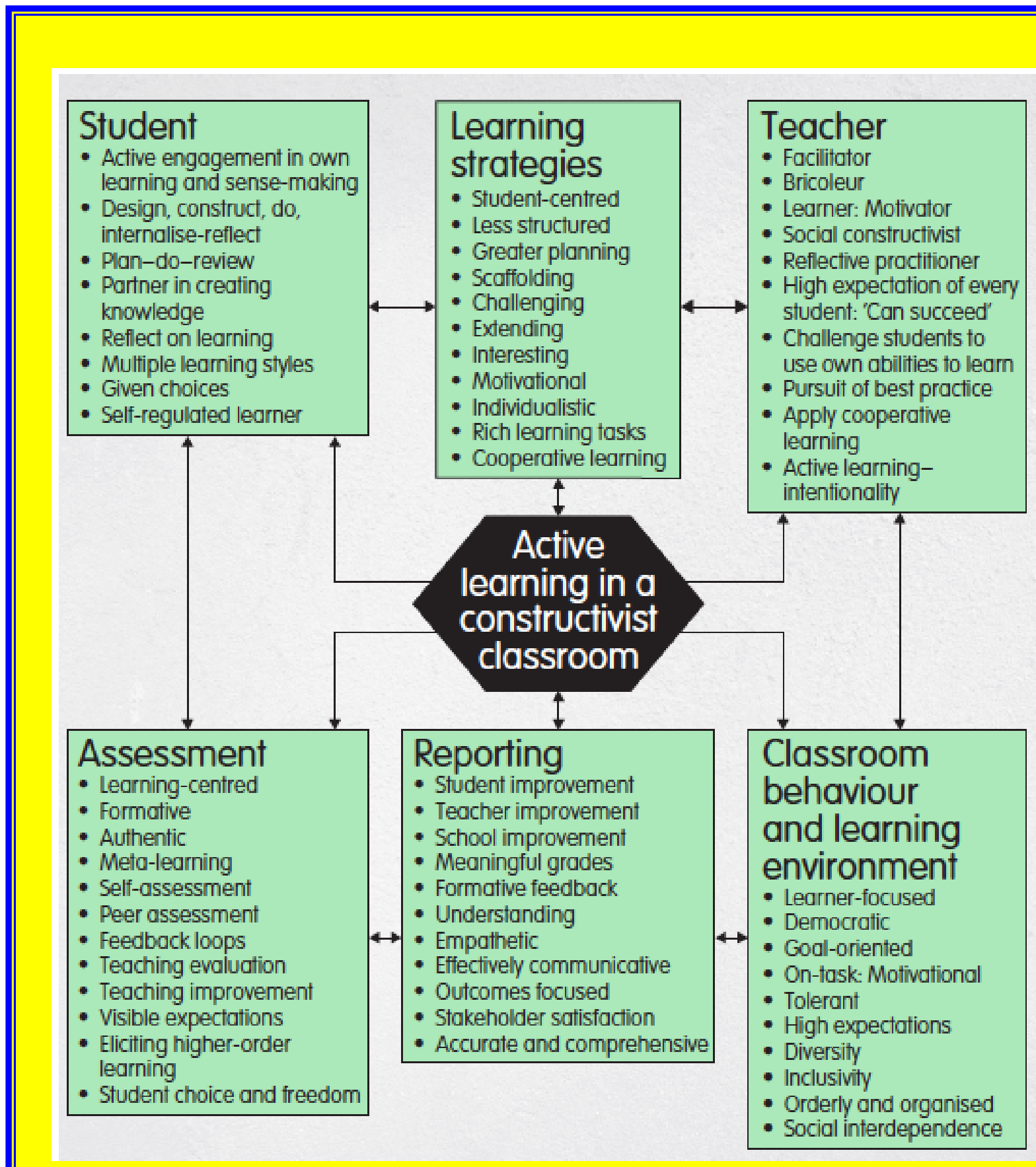

Source: Kivunja, C. (2015). P. 38.

Figure 1. Theoretical Framework For Investigating Constructivist Teaching

This example shows, that you can develop a theoretical framework for your research, by taking an existing theoretical model, and showing that you have good mastery of what the model says, and that what it says can help you to analyse your own data. As illustrated in this example, you need to engage with the model you have chosen so as to unpack it and to demonstrate your deep understanding of the model. In this example, this means that you explain how each of the elements of the model is theorised to influence learning and teaching. Furthermore, you then 
explain how you will use each of these elements to analyze and make sense of your own research data. A good approach in this process is for you to try to link your explanation to your research question/s and problem to be solved. In other words, how does an application of what the different elements of this model theorize, help you to make meaning of your research data?

\section{How do You Know Whether You Have Developed a Good Theoretical Framework or not?}

These points should help you to answer this question.

- Is my theoretical framework clearly seen as emerging from my literature review?

- Is it the result of my analysis of the main theories advanced by leaders in the field in which my research is located?

- Does it represent or is it relevant to the most current state of theoretical knowledge on my topic?

- Have I explained the meaning embedded in the different parts of the theoretical framework?

- Does the theoretical framework present a logical, coherent, analytical structure that will be a good coat hanger for my data analysis?

- Do the different parts of the theory constitute a coherent, and comprehensive model that is capable of helping me to analyse the relationships among the variables I plan to investigate?

- Does the theoretical framework target how I will answer my research questions or test the hypotheses?

- Have I documented every source I have used in developing this theoretical framework?

- Is my theoretical framework a Model, a Table, a Figure or a description?

- Have I explained and justified why this is the appropriate theoretical framework for my data analysis?

\section{Conclusion}

Let me conclude this paper by highlighting the fact that this paper has tried to make a contribution to knowledge by addressing a trifecta of problematic concepts that HDR students and early career researchers often find confusing. As discussed in the paper, the trifecta entails the differences between a theory, a theoretical framework and a conceptual framework. The paper has made it very clear that whereas the theoretical framework is drawn from the existing theoretical literature that you review about your research topic, a conceptual framework is a much broader concept that encompasses, practically all aspects of your research. The latter refers to the entire conceptualisation of your research project. It is the big picture, or vision, comprising the totality of your HDR project. So, it represents all your thinking that goes into the cognitive processing about your research topic, developing interest in it and defining it accurately; finding who will be your supervisors, followed by every step of the entire research process, all the way to completing and submitting your dissertation, and might even include who will be your external examiners. In universities where a thesis requires an oral defence, (often called a viva voce, Latin meaning by live voice), conceptualisation of the respective HDR project includes consideration of and designing the strategies that will be used to defend the thesis. In conclusion, every good thesis should contain a theoretical framework for the analysis of the data. However, there is no requirement for an articulation of the conceptual framework. Ideally, your theoretical framework should emerge from your literature review. This contrasts significantly with your conceptual framework, which, in the main, comprises your own thinking, about all the different components of your research (including the theoretical framework), as explained above. Thus, whereas every dissertation should contain a section titled theoretical framework; and if a doctoral thesis a chapter of this title, there is no requirement that you have a section or chapter discussing the conceptual framework for your research project. It is the expectation that a graduate from a good university, will have a good understanding of the three concepts discussed in this paper, and be able to use them in their research, publications, teaching and discourse, without confusion. I hope that this paper has helped in enabling the reader to meet these expectations.

\section{References}

Asher, H. B. (1984). Theory-building and data analysis in the social sciences. Knoxville, TN: University of Tennessee Press.

Boyd, J. (2013). Active Learning and Co-operation: A Compendium of Generic Teaching and Learning Strategies K-12. Global Learning Communities. Accessed online on 26 November 2013, at: http://www.vision.net.au/_globallearning/pdfs/samples/ACTIVE_LEARNING.pdf

Bunge, M. (1967). Scientific research 1: The search for system. New York, NY: Springer-Verlag. 
Carnes, M. C. (2011). Setting Students’ Minds on Fire, Chronicle of Higher Education, 57(27), 72.

Gabriel, A. (2008). The meaning of theory. Sociological Theory, $26, \quad 173 \quad-\quad 199$. https://doi.org/10.1111/j.1467-9558.2008.00324.x

Glanz, K. (2008). Health behavior and health education: theory, research, and practice. San Francisco: Jossey-Bass Inc.

Glanz, K. (2017). Social and behavioral theories. Behavioral and Social Sciences Research. Accessed online at: www.esourceresearch.org/Portals/)/Uploads/Documents/Public/Glanz_FullChapter.pdf

Guba, E. G. (1981). Criteria for assessing the trustworthiness of naturalistic inquiries, Educational Communication and Technology Journal, 29, 75-91.

Hunt, S. D. (1991). Modern marketing theory: critical issues in the philosophy of marketing science. Cincinnati, OH: Southwestern Publishing.

Jacard, J. \& Jacob, J. (2010). Theory construction and model-building skills: A practical guide for social scientists. New York, NY: Guilford Press.

Johnson, R.B. \& Christensen, L. (2017). Educational research: quantitative, qualitative, and mixed approaches. Los Angeles: Sage.

Kerlinger, F. N. \& Lee, H. B. (2000). Foundations of behavioural research. $4^{\text {th }}$ Edn. Belmont, CA: Cengage Learning.

Kivunja, C. (2015). Teaching, learning and assessment: Steps towards creative Practice. Melbourne, Vic: Oxford University Press.

Neuman, W. L. (1997). Social research methods: Qualitative and quantitative approaches. London: Allyn \& Bacon.

NSW DET. (2013). Quality teaching in NSW Public Schools: Discussion Paper, Professional Support and Curriculum Directorate, Sydney, May 2003. https://www.det.nsw.edu.au/proflearn/docs/pdf/qt_EPSColor.pdf Accessed 18 October 2013.

Popper, K. R. (1985). Falsificationism versus conventionalism. In D. Miller, (Ed). Popper Selections (pp. 143 - 151 ). Princeton, NJ: Princeton University Press.

Ravitch, S. M. \& Riggan, M. (2017). How conceptual frameworks guide research. $2^{\text {nd }}$ Edn. Los Angeles, CA: Sage.

Reynolds, P. D. (1971). A primer in theory construction. Indianapolis, IN: Bobbs-Merrill Educational Publishing.

Scott. D. \& Usher, R. (2004). Researching education: Data, methods, and theory in educational enquiry. New York: Continuum.

Swanson, R. A. (2013). Theory building in applied disciplines. San Francisco, CA: Berrett-Koehler.

Wacker, J. G. (1998). A definition of theory: research guidelines for different theory-building research methods in operations management. Journal of Operations Management, $\quad 16 . \quad 361 \quad-\quad 385$. https://doi.org/10.1016/S0272-6963(98)00019-9 